\title{
Chemical Composition and Inhibition Effect of Eucalyptus Botryoides on the Corrosion of C38 Steel in Hydrochloric Acid Solution
}

\author{
Loubna Koursaoui 1,2, Younes Kerroum ${ }^{2}$, Mohamed Tabyaoui ${ }^{2}$, Abdallah Guenbour ${ }^{2}$, Abdelkabir \\ Bellaouchou ${ }^{2}$, Badr Satrani ${ }^{1}$, Mohamed Ghanmi ${ }^{1}$, Ismail Warad ${ }^{3}$, Abdelaziz Chaouch ${ }^{4}$, \\ Abdelkader Zarrouk ${ }^{2}$,*iD \\ 1 Laboratories of Microbiology and Chemistry of Aromatic and Medicinal Plants, Forest Research Center, BP 763, Agdal, \\ Rabat, Morocco \\ 2 Laboratory of Materials, Nanotechnology, and Environment, Faculty of Sciences, Mohammed V University, P.O. Box. \\ 1014 Agdal-Rabat, Morocco \\ 3 Department of Chemistry and Earth Sciences, PO Box 2713, Qatar University, Doha, Qatar \\ 4 Biotechnology, Environment and Quality Laboratory, Faculty of Sciences, Ibn-Tofail University, BP 133, Kenitra, 14000, \\ Morocco \\ * Correspondence: azarrouk@gmail.com;
}

Scopus Author ID 36125763200

Received: 14.09.2020; Revised: 10.10.2020; Accepted: 10.10.2020; Published: 12.10.2020

\begin{abstract}
In this paper research, the inhibition effect of Eucalyptus Botryoides essential oil (EO) on the corrosion of C38 steel in hydrochloric acid solution was investigated. Gravimetric method and electrochemical measurements, SEM morphology, and EDS analysis were used to verify this effect. The gravimetric results were showed that the concentration effect decreases the corrosion rate of C38 steel, which was confirmed by the electrochemical measurements. The potentiodynamic polarization results were exhibited that the EO inhibits the anodic and cathodic sites on the metal surface, and the EIS results were showed that the EO decreases the charge transfer at the interface metal/solution, without change the mechanism. The inhibition efficiency was found in order of $90 \%$ at a maximum concentration of $2.4 \mathrm{~g} / \mathrm{L}$. SEM morphology and EDS analysis were proved the effective inhibition of EO by forming a protective film. The temperature effect was also realized, and the results show that the EO is also an effective inhibitor at high temperatures. These findings will have significant results in regard to industrial applications.
\end{abstract}

Keywords: inhibition; steel; essential oil; hydrochloric acid solution; EIS; SEM/; EDS.

(C) 2020 by the authors. This article is an open-access article distributed under the terms and conditions of the Creative Commons Attribution (CC BY) license (https://creativecommons.org/licenses/by/4.0/).

\section{Introduction}

The protection of carbon steel against the corrosion phenomena has been widely studied by different methods[1-8], but the inhibition method remains one of the most used methods due to the economic and environmental considerations. That is why different actions must be taken into account when using the inhibitor in industrial sectors, such as toxicity for the environment and human health. In industry, especially the use of acidic media for pickling and cleaning of steel, the degradation of carbon steel is a real problem. Either way, synthetic inhibitors have been investigated, where organic molecules tend to adsorb to the metal surface, due to the molecular structure that contains polar sites of heteroatoms and the conjugate bonds, aromatic rings, which serve to block the active sites on the metal surface, but the disadvantage that the majority are not eco-friendly. And recently, essential oils have gained attention as a 
resource of eco-friendly natural products. They have been preferred for their potential uses as an antibacterial inhibitor and as a chemical additive for corrosion protection $[9,10]$. Indeed, essential oils of Eucalyptus species have been exploited, and many studies have demonstrated their antimicrobial properties against a wide range of microorganisms, but their anti-corrosion properties, only a few studies have exploited these properties. In previous studies[11,12], they studied Eucalyptus as a green corrosion inhibitor against the degradation of C38 steel in aggressive solutions. The results obtained showed a positive sign of corrosion inhibition. Through these studies, the authors link the effect of essential oil on corrosion protection to natural species such as oxygenated monoterpenes and sesquiterpenes, monoterpene hydrocarbons, and ketones. Our research has focused on finding an inhibitor characterized by its antibacterial and anti-corrosive inhibition. We are interested in studying the inhibitory effect of Eucalyptus Botryoides on the deterioration of C38 steel in a hydrochloric acid solution (1M $\mathrm{HCl}$ ), which has not been tested before, using different techniques and methods, such as weight loss, potentiodynamic polarization, and electrochemical impedance spectroscopy methods (EIS), scanning electron microscopy (SEM) and energy-dispersive spectroscopy analysis (EDS).

\section{Materials and Methods}

\subsection{Extraction of essential oil.}

The Essential Oil (EO) of Eucalyptus Botryoides was performed by hydrodistillation in a Clevenger-type apparatus[13]. The method applied is that described in the European Pharmacopoeia in 2008 and according to the 2008 recommendations of the French Health Products Safety Agency. We performed three distillations by boiling $200 \mathrm{~g}$ of vegetal material cut with pruning shears and introduced into a 2-liter flask containing 1 liter of water. The extraction time is of the order of 3 hours on average. The (EO) obtained is dehydrated with anhydrous sodium sulfate and then stored at a low temperature (below $4{ }^{\circ} \mathrm{C}$ ) and in the dark before use. Then, it was diluted in methanol (1/20 v/v) prior to analysis by GC and GC/MS according to AFNOR standard; the chemical compositions of the EO are shown in Table 1.

\subsection{Materials.}

The material used in this study was C38 steel with the composition of $(0.179 \% \mathrm{C}$, $0.165 \% \mathrm{Si}, 0.439 \% \mathrm{Mn}, 0.203 \% \mathrm{Cu}, 0.034 \% \mathrm{~S}$, and Fe balance). Before each test, the samples were polished with emery paper grade from 180 up to1200, washed and degreased with distilled water and acetone, respectively. For electrochemical measurements, the working electrode was with a surface area of $1 \mathrm{~cm}^{2}$, and for weight loss studies, the dimension of the samples was $2 \times 1 \times 0.3 \mathrm{~cm}^{3}$.

\subsection{Preparation of the solutions.}

EO inhibitor was prepared in the dilution Hydrochloric acid $\mathrm{HCl}(1 \mathrm{M})$ from an analytical grade $37 \% \mathrm{HCl}$, with these concentrations $0.1 \mathrm{~g} / \mathrm{L}, 0.6 \mathrm{~g} / \mathrm{L}, 1.8 \mathrm{~g} / \mathrm{L}, 2.4 \mathrm{~g} / \mathrm{L}$. The anticorrosion effect of the inhibitor was compared with the dilution Hydrochloric acid (1M), in the absence of the EO (blank solution). 


\subsection{Electrochemical measurements.}

The anti-corrosion effect of the EO on the C38 steel was approved by using the electrochemical measurements, such as the potentiodynamic polarization and electrochemical impedance spectroscopy (EIS). For that, three-electrodes were utilized, the working electrode (C38steel), the counter electrode (platinum), and the saturated calomel electrode (SCE) as a reference electrode. This electrochemical cell was controlled by the VoltaMaster 4 software using the potentiostat PGZ 301 (Radiometer Analytical). The polarization parameters were $0.5 \mathrm{mV} / \mathrm{s}$ of scan rate in the range of $-600 \mathrm{mV} / \mathrm{SCE}$ to $-200 \mathrm{mV} / \mathrm{SCE}$ and the EIS parameters were with the sine wave voltage $(10 \mathrm{mV})$ peak to peak, at frequencies from $100 \mathrm{kHz}$ to 10 $\mathrm{mHz}$. The curves were plotted after the stabilization potential. The temperature effect was obtained at $298 \mathrm{~K}, 313 \mathrm{~K}, 323 \mathrm{~K}, 333 \mathrm{~K}$.

\subsection{Scanning electron microscopic and energy dispersive spectroscopy analysis.}

The Scanning electron microscopic (SEM) (JEOL JSM-IT 100) and the energy dispersive spectroscopy (EDS) analysis were used to study morphology and qualitative analysis of metal surface in this study, with an accelerating voltage of $20 \mathrm{kV}$.

Table 1. Chemical compositions of Essential Oil (\%).

\begin{tabular}{|c|c|}
\hline Compounds & Percentage Compositions \\
\hline$\alpha$-pinene & 55.16 \\
\hline Camphene & 2.46 \\
\hline Thuja-2,4 (10)-diene & 0.16 \\
\hline$\beta$-pinene & 0.41 \\
\hline$\delta$-2-carene & 0.12 \\
\hline$\alpha$-phellandrene & 0.15 \\
\hline p-cymene & 2.05 \\
\hline 1,8 cineole & 3.61 \\
\hline (3E)-octen-2-one & 6.1 \\
\hline cis-linalool oxide & 0.11 \\
\hline Trans-linalool oxide & 0.57 \\
\hline linalool & 0.07 \\
\hline Endo-fenchol & 1.36 \\
\hline$\alpha$-campholenal & 0.59 \\
\hline Trans-dihydro- $\alpha$-terpineol & 12.84 \\
\hline$\beta$-pinene oxide & 0.65 \\
\hline Borneol & 3.16 \\
\hline Terpin-4-ol & 2.16 \\
\hline p-cymene-8-ol & 0.41 \\
\hline Cis-dihydro-carvone & 2.74 \\
\hline$\gamma$-terpineol & 0.3 \\
\hline citronellol & 0.18 \\
\hline Cis-pulegol & 0.48 \\
\hline Carvone & 0.26 \\
\hline Cis -verbenylacetate & 0.11 \\
\hline$\beta$-humulene & 0.17 \\
\hline$\alpha$-humulene & 0.19 \\
\hline Spathulenol & 0.06 \\
\hline trans- $\beta$-elemenone & 0.25 \\
\hline (E)-isoeugenolacetate & 0.08 \\
\hline
\end{tabular}

\section{Results and Discussion}

\subsection{Weight loss study.}

The weight-loss study was performed in the absence and present different concentrations of EO inhibitor, and the results were presented in Table 2. In general, this method is important, and it is complimentary to electrochemical measurements. The method is 
based on calculating the corrosion rate $(\mathrm{W})$ of material from the mass variation at a defined time (Equation 1)[14-16].

$$
\mathrm{W}=\frac{\mathrm{m}_{\mathrm{i}}-\mathrm{m}_{\mathrm{f}}}{\mathrm{S} \times \mathrm{t}}
$$

$\mathrm{m}_{\mathrm{i}}(\mathrm{mg})$ and $\mathrm{m}_{\mathrm{f}}(\mathrm{mg})$ are the mass of the samples before and after the immersion time, respectively. $\mathrm{S}\left(\mathrm{cm}^{2}\right)$ is the sample surface, and $\mathrm{t}(\mathrm{h})$ represents the time of immersion. From the results obtained, we remark that the corrosion rate is decreased in the presence of the EO inhibitor, and this effect is more pronounced when its concentration is increased (Figure 1). This observation is expressed as the efficiency percentage by equation $2[17,18]$ :

$$
\mathrm{E}(\%)=\frac{\mathrm{w}_{0}-\mathrm{W}_{\mathrm{inh}}}{\mathrm{W}_{0}} \times 100(2)
$$

$\mathrm{W}_{0}$ and $\mathrm{W}_{\text {inh }}$ are the symbols of the corrosion rate without and with the EO inhibitor, respectively.

Table 2. Weight loss results of the samples without and with different concentrations of EO inhibitor.

\begin{tabular}{l|c|c|c|c|c}
$\mathbf{C}(\mathbf{g} / \mathbf{L})$ & $\mathbf{0}$ & $\mathbf{0 . 1}$ & $\mathbf{0 . 6}$ & $\mathbf{1 . 8}$ & $\mathbf{2 . 4}$ \\
\hline $\mathrm{W}\left(\mathrm{mg} \mathrm{cm}^{-2} \mathrm{~h}^{-1}\right)$ & 0.224 & 0.085 & 0.058 & 0.023 & 0.016 \\
\hline $\mathrm{E}(\%)$ & - & 62 & 74 & 81 & 87
\end{tabular}

The results obtained show that the lowest efficiency is recorded at the concentration of $0.1 \mathrm{~g} / \mathrm{L}$, and the high value is registered at the concentration of $2.4 \mathrm{~g} / \mathrm{L}$ (Table 2). Furthermore, the increase in the inhibitor concentration from $0.1 \mathrm{~g} / \mathrm{L}$ to $2.4 \mathrm{~g} / \mathrm{L}$ changes the efficiency from $62 \%$ to $87 \%$. This effect may be elucidated by the adsorption mechanism of the organic compounds that forming the EO. Indeed, the organic compounds participate in the inhibition mechanism by forming links with the active sites on the metal surface through the heteroatom's or double and triple bonds that exist in the organic compounds[19-21]. Another study was performed on the commercial oil of Eucalyptus by Hafez showed high-efficiency values (93\%) at a concentration of $1 \mathrm{~g} / \mathrm{L}[22]$. This distinction may be correlated to the sources and Chemical composition of EOs. However, the competitive inhibition with different compounds of EO inhibitor can also influence the inhibition efficiency by several factors such as the molecule's nature and type. Anyway, the results show an efficient corrosion inhibition and provide evidence that the EO Eucalyptus Botryoides is an eco-friendly inhibitor.

\subsection{Potentiodynamic polarization measurements.}

The potentiodynamic polarization was used to study the effect of EO on the corrosion parameters values of the samples. Figure 1 shows the current densities variation as a function of the potential that applicated to the samples. The effect of EO on both anodic and cathodic curves was observed as its concentration was increased. To explain this tendency, the corrosion parameters were extracted from the curves using the Tafel extrapolation. The obtained results were regrouped in Table 3.

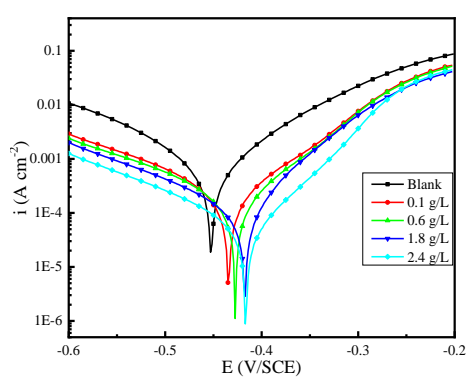

Figure 1. Effect of EO concentration on the polarization curves of the $\mathrm{C} 38$ steel in $1 \mathrm{M} \mathrm{HCl}$. 
Table 3 exhibits in the presence of the EO that the corrosion potential shifts from -452 to $-417 \mathrm{mV} / \mathrm{SCE}$, but do not exceed $85 \mathrm{mV}$ [23-25]. As a result, this inhibitor can be classified as a mixed inhibitor. Moreover, Figure 1 confirms this tendency, and it shows that both cathodic and anodic branches are under the reference curve of a blank solution. This remarkable change may explain that inhibitor blocks the anodic and cathodic active sites on the metal surface. Furthermore, Table 3 shows that the anodic slope remarkably changed compared to the cathodic slop. This observation allows us to suggest that inhibitor altering the anodic reaction's mechanism.

Table 3. Effect of EO concentration on the corrosion parameters of $\mathrm{C} 38$ steel in $1 \mathrm{M} \mathrm{HCl}$.

\begin{tabular}{l|c|c|c|c|c}
$\begin{array}{l}\text { Conc. } \\
(\mathbf{g} / \mathbf{L})\end{array}$ & $\begin{array}{c}-\mathbf{E}_{\mathbf{c o r r}} \\
(\mathbf{m V} / \mathbf{S C E})\end{array}$ & $\begin{array}{c}\mathbf{i}_{\mathbf{c}} \\
\left(\boldsymbol{\mu} \mathbf{A} / \mathbf{c m}^{2}\right)\end{array}$ & $\begin{array}{c}\boldsymbol{\beta}_{\mathbf{a}} \\
(\mathbf{m V / d e c})\end{array}$ & $\begin{array}{c}\mathbf{\beta}_{\mathbf{c}} \\
(\mathbf{m V / d e c})\end{array}$ & $\begin{array}{c}\mathbf{E} \\
(\mathbf{\%})\end{array}$ \\
\hline 0.0 & 452 & 787.6 & 108.2 & 125.7 & - \\
\hline 0.1 & 434 & 199.9 & 86.4 & 136.6 & 74 \\
\hline 0.6 & 427 & 179,8 & 83.2 & 149.9 & 77 \\
\hline 1.8 & 418 & 153.5 & 81.5 & 173.6 & 81 \\
\hline 2.4 & 417 & 54.6 & 67.4 & 130.7 & 93
\end{tabular}

The corrosion current density is also obtained, a significant decrease is remarked at the presence of the EO, especially at $2.4 \mathrm{~g} / \mathrm{L}$, and the obtained efficiency is about $93 \%$. The probable reason for this behavior is due to the adsorption process because most of the organic inhibitors act as an adsorbed agent on the material surface in the acidic medium [26-28]. In the literature[29-32], the adsorption action of the organic inhibitors on metal surfaces has been studied by different adsorption isotherms. As the EOs have different compositions, the applicable adsorption isotherms are under debate, for the reason that the thermodynamics uses exclusively to the equilibrium system, and due to the complexity of operating adsorption mechanisms of the EO molecules on the metal surface.

\subsection{Electrochemical impedance spectroscopy (EIS).}

The electrochemical impedance spectroscopy technique is used to control the corrosion reaction process that occurs at the interface metal/solution. Figure 2 shows the Nyquist plots of the impedance data, and it exhibits a depressed capacitive semicircle. Many authors relate this capacitive behavior to the corrosion reaction process that occurs under the control of the charge transfer [33,34]. The depressed semicircle of the plots may be related to the nature of the solution and the state of the material surface[35], or to the fast absorption of the intermediate products [36]. Another observation, the semicircle rises with increasing the EO concentration, which indicates a decrease in the charge transfer process; as a consequence, it's a sign of metal protection amelioration.

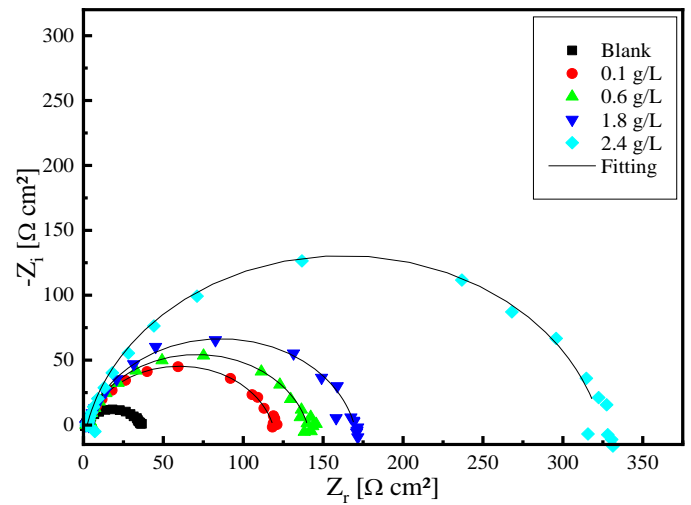

Figure 2. Effect of EO concentration on the electrochemical impedance plots (Nyquist plots) of the C38 steel in $1 \mathrm{M} \mathrm{HCl}$. 
Furthermore, the fitting of the obtained data lets us understand the behavior of metal in the absences and in the presence of the EO. For that, it's crucial to choose the right equivalent circuit that describes the different process that occurs at the interface metal/solution. In general, the simple semicircle is simulated by an equivalent circuit that describes the electrolyte resistance $\left(R_{s}\right)$, charge transfer resistance $\left(R_{c t}\right)$, constant phase element (CPE) (Figure3).

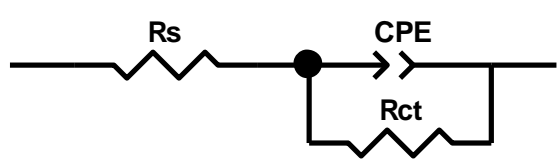

Figure 3.Electrical equivalent circuit that describes the interface metal/solution without and with the EO.

The impedance of CPE is represented by this function[37]:

$$
Z_{C P E}=\frac{1}{Y_{0}(j \omega)^{n}}(3)
$$

Eq. (4) establishes the relation between CPE impedance and $C_{d l}$

$$
C_{d l}=\left(Y_{0}^{1 / n}\left(R_{P}\right)^{1-n / n}\right)
$$

$Y_{o}$ and $n$ represent the magnitude of CPE and phase shift, respectively, and $\omega$ is the angular frequency at the maximum point of the imaginary impedance of the Nyquist plots. This selected circuit explains the electrochemical process of the dissolution mechanism, which the doublelayer capacitance and charge transfer is occurring in parallel and in serial with the electrolyte resistance. The extracted impedance parameters are listed in Table 4.

\begin{tabular}{|c|c|c|c|c|c|c|}
\hline Conc.(g/L) & $\begin{array}{c}\mathbf{R}_{\mathrm{s}} \\
\left(\Omega \mathrm{cm}^{2}\right)\end{array}$ & $\begin{array}{c}Y_{0}\left(\times 10^{4}\right) \\
\left(\Omega^{-1} \mathrm{sn} \mathrm{cm}^{-2}\right)\end{array}$ & $\mathbf{n}$ & $\begin{array}{c}\mathbf{R}_{\mathrm{ct}} \\
\left(\Omega \mathrm{cm}^{2}\right)\end{array}$ & $\begin{array}{c}\mathbf{C}_{\mathrm{dl}} \\
\left(\mu \mathrm{F} \mathbf{c m}^{-2}\right)\end{array}$ & $\begin{array}{c}\mathbf{E} \\
(\%)\end{array}$ \\
\hline Blank & 1.28 & 3.48 & 0.805 & 34.21 & 119.60 & - \\
\hline 0.1 & 1.71 & 1.79 & 0.838 & 117.30 & 84.68 & 71 \\
\hline 0.6 & 1.89 & 1.34 & 0.848 & 138.30 & 65.89 & 76 \\
\hline 1.8 & 2.37 & 1.28 & 0.856 & 167.10 & 66.62 & 80 \\
\hline 2.4 & 2.31 & 0.76 & 0.868 & 325.60 & 43.52 & 90 \\
\hline
\end{tabular}

Table 4. Effect of EO concentration on the electrochemical impedance parameters of the C38 steel in $1 \mathrm{M} \mathrm{HCl}$.

In addition, the results show that the charge transfer resistance is increased, and the double layer capacitance is decreased as the concentration of the EO rises, which affects the efficiency of inhibition. This efficiency is calculated from the following equation 5 [38]:

$$
\mathrm{E}(\%)=\frac{R_{c t}-R_{c t}^{0}}{R_{c t}} \times 100
$$

where $\mathrm{R}_{\mathrm{ct}}^{0}$ and $\mathrm{R}_{\mathrm{ct}}$ are the charge transfer resistance values without and with the EO inhibitor, respectively. Moreover, the efficiency is increased from $71 \%$ to $90 \%$ when the concentration is augmented from $0.1 \mathrm{~g} / \mathrm{L}$ to $2.4 \mathrm{~g} / \mathrm{L}$, respectively. This behavior may result from the adsorption of the EO molecules on the metal surface, which establishes a protective barrier against the corrosive solution. The barrier formed decreases the surface contact of metal with its environment; this leads to a decline in the local dielectric constant and increases the resistance capability of the metal to react with its environment. We also noted that efficiency grows to be high after the concentration exceeds the $0.6 \mathrm{~g} / \mathrm{L}$. This tendency may be explained by that the effective barrier starts at this concentration, which depends on many restrictions like the nature of organic compounds of the EO, the metal surface, and the aggressive environment. It's known that the EO product contains a wide chemical composition that has different percentages, sizes, active centers, and chemical proprieties. For that, the competitive 
effect may occur, or the chemical compounds that responsible for the inhibition are in a lower concentration. Another observation of Table 4 exhibits that the CPE constant Yovalue experienced a significant decline, which means that the EO interacts with the C38 steel electrode by occupying the vacate active sites. Further, the elevation of the $n_{\text {values of EO }}$ relative to the uninhibited electrolyte can be related to a reduction of electrode surface roughness.

\subsection{Temperature effect.}

The inhibition efficiency at different temperatures and the thermodynamic parameters of the corrosion process was investigated in the presence of the EO using the electrochemical impedance spectroscopy measurements. The temperature range (298-333 K) was used to study this effect at the optimum concentration of $2.4 \mathrm{~g} / \mathrm{L}$ of the $\mathrm{EO}$ (Figure 4 ). As shown in this Figure, the temperature elevation affects the impedance of $\mathrm{C} 38$ steel, but it is less than in the presence of the EO. On the other hand, the charge transfer mechanism predominates on the interaction between the metal surface and the electrolyte, and the temperature decreases the diameter of the semicircle, both in the blank solution and in the presence of the EO.
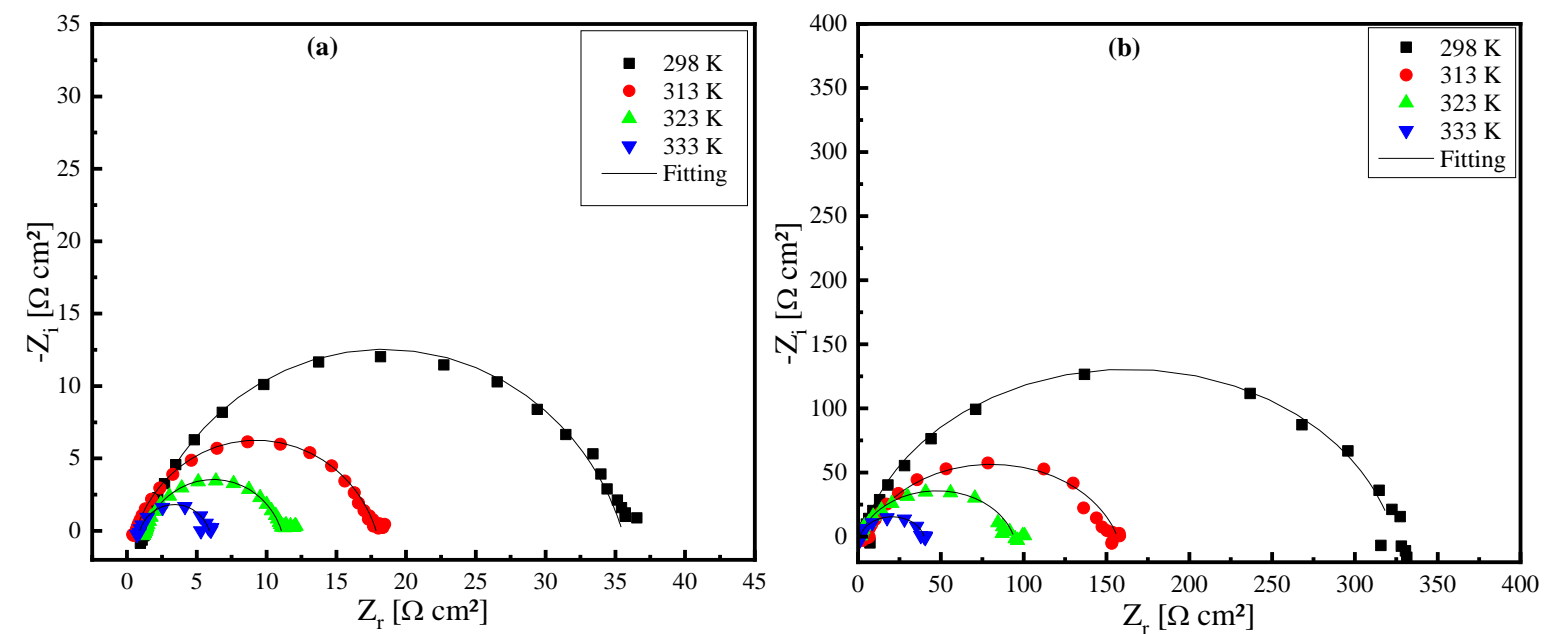

Figure 4. Effect of temperature on the Nyquist plots of $\mathrm{C} 38$ steel in $1 \mathrm{M} \mathrm{HCl}$ (a) without and (b) with $2.4 \mathrm{~g} / \mathrm{L}$ of the EO.

Furthermore, the electrochemical impedance parameters are listed in Table 5 to evaluate the effect of temperature on the corrosion inhibition efficiency. Following the data showing in Table 5, the charge transfer resistance is enlarged in the presence of the inhibitor, which means that the inhibitor attenuates the effect of temperature. This implies that the inhibitor reduces the dissolution of the metal. The corrosion inhibition efficiency is also calculated, as shown in Table 5; the results show that the efficiency is high, but less than $90 \%$ at different temperatures. These values may be related to the chemisorption mechanism, which is well known; it provides high inhibition efficiency with the elevation of temperature[36]. Moreover, organic inhibitors are largely used for acid environments to slow the corrosion rate of metals [39-42]. Most of them are the molecules with linear or branched chains or aromatic compounds, typically include polar and non-polar functional groups. All of these molecular structure properties are responsible for the inhibition efficiency. The high inhibition efficiency at elevated temperature means the presence of strong adsorption of the EO molecules on the metal surface. In general, there are three types of adsorption mechanisms of organic inhibitors: electrostatic adsorption, $\pi$-orbital bond adsorption, and chemisorptions. Salarvand et al. have 
attached this behavior to the acid-base reaction between the organic molecules and the metal surface [36].

Table 5. Effect of temperature on the electrochemical impedance parameters of $\mathrm{C} 38$ steel in $1 \mathrm{M} \mathrm{HCl}$ without and with $2.4 \mathrm{~g} / \mathrm{L}$ of the EO.

\begin{tabular}{|c|c|c|c|c|c|c|c|c|}
\hline & Temperature & $\begin{array}{c}\mathbf{R s}_{\mathrm{s}} \\
\left(\Omega \mathrm{cm}^{2}\right)\end{array}$ & $\begin{array}{c}\mathbf{Y}_{0}\left(\times 10^{4}\right) \\
\left(\Omega^{-1} \mathbf{s n ~ c m}^{-2}\right)\end{array}$ & $\mathbf{n}$ & $\begin{array}{c}\mathbf{R}_{\mathrm{ct}} \\
\left(\Omega \mathrm{cm}^{2}\right)\end{array}$ & $\begin{array}{c}\mathrm{C}_{\mathrm{dl}} \\
\left(\mu \mathrm{F} \mathbf{c m}^{-2}\right)\end{array}$ & $\begin{array}{c}\text { icorr } \\
\left(\mathbf{m A} / \mathbf{c m}^{2}\right)\end{array}$ & $\underset{(\%)}{E}$ \\
\hline \multirow{4}{*}{ Blank } & 298 & 1.28 & 3.48 & 0.805 & 34.21 & 119.60 & 0.375 & - \\
\hline & 313 & 0.65 & 5.17 & 0.804 & 17.20 & 163.50 & 0.784 & - \\
\hline & 323 & 1.31 & 5.64 & 0.801 & 9.75 & 155.40 & 1.420 & - \\
\hline & 333 & 0.90 & 7.60 & 0.802 & 4.99 & 192.10 & 2.870 & - \\
\hline \multirow{4}{*}{ EO } & 298 & 2.31 & 0.76 & 0.868 & 325.60 & 43.52 & 0.0394 & 89 \\
\hline & 313 & 4.50 & 1.36 & 0.812 & 152.00 & 55.63 & 0.0887 & 88 \\
\hline & 323 & 1.11 & 0.94 & 0.834 & 92.89 & 36.94 & 0.150 & 89 \\
\hline & 333 & 1.14 & 0.99 & 0.855 & 38.74 & 38.87 & 0.370 & 87 \\
\hline
\end{tabular}

For more investigation, the corrosion current density ( $\left.\mathrm{i}_{\text {corr }}\right)$ is calculated from the impedance results by using equation 6 [27]:

$$
i_{\text {corr }}=\frac{R T}{z F R_{p}}(6)
$$

Where, $\mathrm{R}$ is the universal gas constant $\left(8.314 \mathrm{~J} \mathrm{~K}^{-1} \mathrm{~mol}^{-1}\right)$, and $\mathrm{T}(\mathrm{K})$ represents the temperature effect. The iron valence $(\mathrm{z}=2)$ and the Faraday constant $(\mathrm{F}=96485$ Coulomb) are regrouped with the polarization resistance $\left(\mathrm{R}_{\mathrm{ct}}\right)$. In this study, the polarization resistance $\mathrm{R}_{\mathrm{p}}$ is replaced by the charge transfer resistance $\mathrm{R}_{\text {ct. }}$. After that, the variation of corrosion current density as a function of temperature is traced to extract the corrosion process parameters such as the activation energy and enthalpy and the entropy from the equations 7 and 8 [7] as shown in Figure5.

$$
\begin{gathered}
i_{c o r r}=K \exp \left(\frac{-E_{a}}{R T}\right)(7) \\
i_{c o r r}=\frac{R T}{N h} \exp \left(\frac{\Delta S_{a}}{R}\right) \exp \left(\frac{-\Delta H_{a}}{R T}\right)(8)
\end{gathered}
$$

$\mathrm{i}_{\text {corr }}$ is the corrosion rate density, $\mathrm{E}_{\mathrm{a}}$ represents the activation energy, $\Delta \mathrm{H}_{\mathrm{a}}$ is the activation enthalpy, $\Delta \mathrm{S}_{\mathrm{a}}$ exhibits the activation entropy, and $\mathrm{K}$ is the Arrhenius pre-exponential factor, $\mathrm{N}$ is the Avogadro's number $\left(6.022 \times 10^{23} \mathrm{~mol}^{-1}\right)$, and h is the Plank's constant $\left(6.6261 \times 10^{-34} \mathrm{~J}\right.$ s).
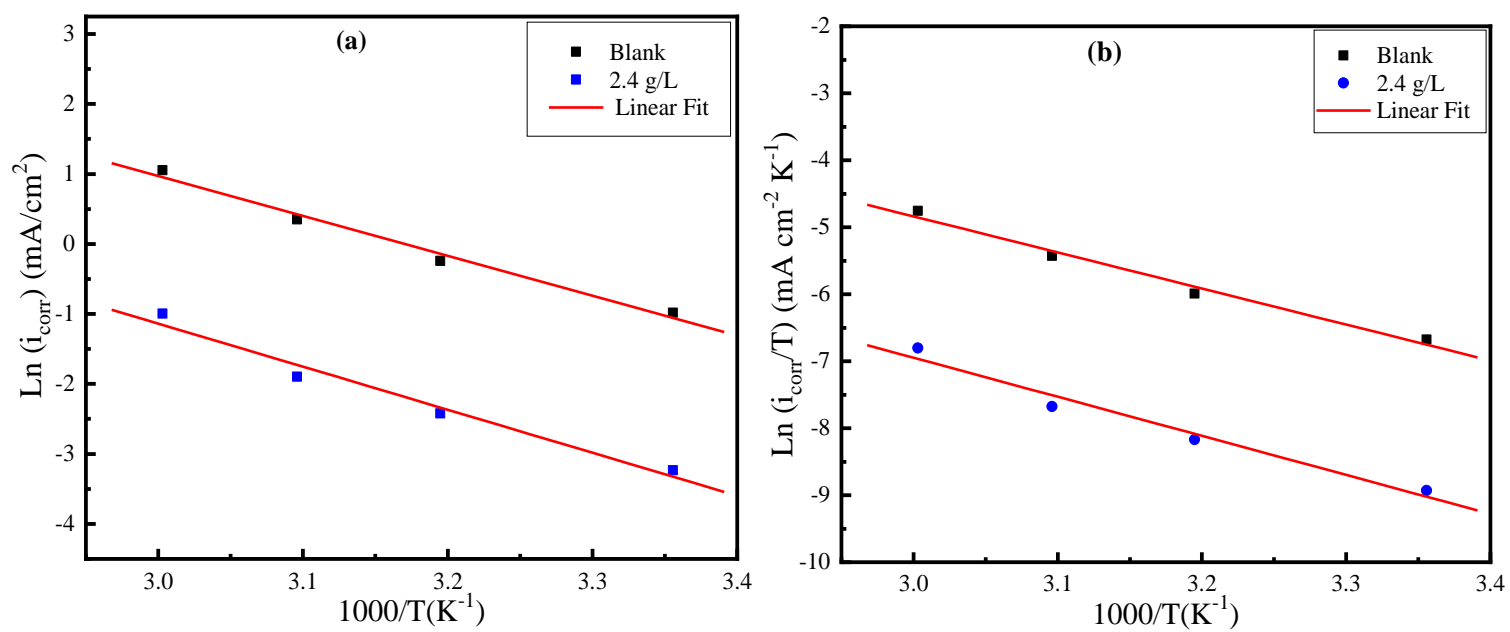

Figure 5. Arrhenius (a) and transition-state (b) plots of C38 steel in $1 \mathrm{M} \mathrm{HCl}$ without and with $2.4 \mathrm{~g} / \mathrm{L}$ of the EO inhibitor.

The results are represented in Table 6. they show an increase of the $\mathrm{Ea}$ and $\Delta \mathrm{H}_{\mathrm{a}}$ in the presence of the EO. This is reflecting the effect of the EO molecules on the dissolution 
mechanism of the metal. The Ea elevation means that the system requires more energy to activate the corrosion process. And the positive value of $\Delta \mathrm{H}_{\mathrm{a}}$ indicates that the inhibitor conserves the endothermic nature of the corrosion process. On the other hand, the $\Delta S_{a}$ is decreased, which reflects a decrease in system disorder.

Table 6. Activation parameters of $\mathrm{C} 38$ steel in $1 \mathrm{M} \mathrm{HCl}$ without and with $2.4 \mathrm{~g} / \mathrm{L}$ of the EO.

\begin{tabular}{l|c|c|c} 
Activation parameters & $\begin{array}{c}\mathbf{E a} \\
\left(\mathbf{k J ~ m o l}^{-\mathbf{1}}\right)\end{array}$ & $\begin{array}{c}\Delta \mathbf{H}_{\mathbf{a}} \\
\left(\mathbf{k J ~ m o l}^{\mathbf{1}}\right)\end{array}$ & $\begin{array}{c}\Delta \mathbf{S}_{\mathbf{a}} \\
\left(\mathbf{J ~ K ~ K}^{-\mathbf{1}} \mathbf{~ m o l}^{\mathbf{- 1}}\right)\end{array}$ \\
\hline Blank & 47.37 & 44.76 & -103.48 \\
\hline $2.4 \mathrm{~g} / \mathrm{L}$ & 51.10 & 48.48 & -109.848
\end{tabular}

\subsection{Surface studies.}

The surface morphology and EDS analysis of the samples are investigated in the absence and presence of the EO after the immersion time of $6 \mathrm{~h}$ (Figure6). The SEM image shows that the sample surface is attacked in the absence of an inhibitor, which proves the aggressiveness of the $\mathrm{HCl}$ solution and the high corrosion rate of the sample(Figure6-a). Besides that, the EDS results demonstrate the presence of a high level of iron and oxygen and a negligible value of chloride on the sample surface. This may be an indication that the surface is rich in iron oxides and hydroxide compounds. In addition, the little value of chloride can relate to the formation of soluble compounds more stable in the solution, such as iron chloride (Table 7).On the other hand, the inhibitory effect of the EO is observed on the sample surface(Figure6-b). The EO exhibits a positive effect which protects the metal from the aggressiveness of the solution. Similarly, the EDS results show an increase in the percentage of carbon and a decrease in the percentage of oxygen and iron (Table 7). Accordingly, these results may explain that the organic species of the EO are adsorbed to the metal surface, which interprets the results obtained from electrochemical studies and weight loss measurements.
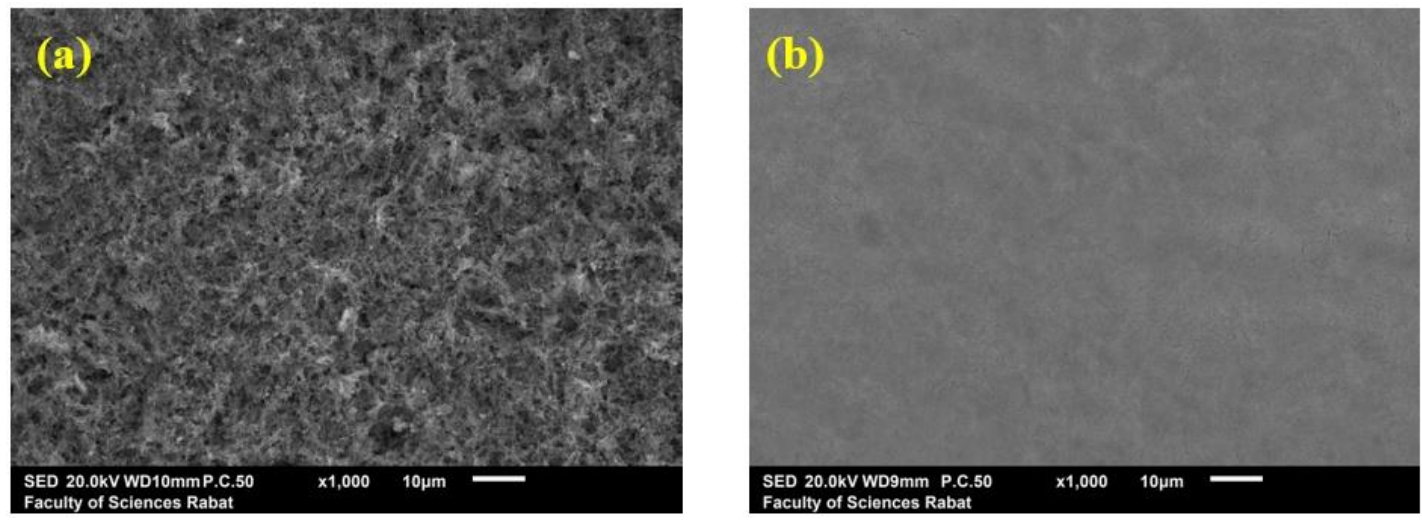

Figure 6. Surface morphology of the $\mathrm{C} 38$ steel in $1 \mathrm{M} \mathrm{HCl}$, (a) without,(b) with $2.4 \mathrm{~g} / \mathrm{L}$ of the EO after $6 \mathrm{~h}$ of immersion.

Table 7. EDS analysis of the $\mathrm{C} 38$ steel in $1 \mathrm{M} \mathrm{HCl}$ without and with $2.4 \mathrm{~g} / \mathrm{L}$ of the $\mathrm{EO}$ after $6 \mathrm{~h}$ of immersion.

\begin{tabular}{c|c|c} 
Mass (\%) & Blank & $\mathbf{2 . 4} \mathbf{~ g / L}$ \\
\hline $\mathrm{C}$ & 05.59 & 25.84 \\
\hline $\mathrm{N}$ & - & 00.24 \\
\hline $\mathrm{O}$ & 18.15 & 15.65 \\
\hline $\mathrm{Cl}$ & 00.30 & 02.19 \\
\hline $\mathrm{Fe}$ & 74.91 & 56.07
\end{tabular}

\section{Conclusions}

The corrosion inhibition technology using the eco-friendly inhibitors are recently studied by scientists to reduce the economic and environmental implications. For that, the 
essential oil of Eucalyptus Botryoides was investigated as an inhibitor for corrosion of C38 steel in $1 \mathrm{M} \mathrm{HCl}$ solution, using electrochemical and spectroscopic techniques, and weight loss. The results were showed a beneficial effect of the EO; the weight loss was exhibited that the EO decreases the corrosion rate of C38 steel. The potentiodynamic polarization measurements were indicated a mixed character of inhibitor, which affects the anodic and cathodic sites of the metal surface. The electrochemical impedance spectroscopy was explained that the corrosion of $\mathrm{C} 38$ steel in $1 \mathrm{M} \mathrm{HCl}$ was under the control of the charge transfer mechanism, and the presence of the EO in the solution decreases the rate of charge transfer at the interface metal/solution. The temperature effect was also studied, and the activation parameters of the corrosion process were extracted; the $\mathrm{EO}$ increases the $\mathrm{E}_{\mathrm{a}}$ and $\Delta \mathrm{H}_{\mathrm{a}}$, and decrease $\Delta \mathrm{S}_{\mathrm{a}}$. The inhibition efficiency remains higher, even the temperature increased, and it has proposed that the adsorption mechanism is dominated by the chemisorptions process. The SEM morphology and EDS analysis were confirmed the beneficial effect of the EO as an eco-friendly corrosion inhibitor for $\mathrm{C} 38$ steel in $1 \mathrm{M} \mathrm{HCl}$ solution.

\section{Funding}

This research received no external funding.

\section{Acknowledgments}

We thank all colleagues.

\section{Conflicts of Interest}

The authors declare no conflict of interest.

\section{References}

1. Saxena, A.; Thakur, K.K.; Bhardwaj, N. Electrochemical studies and surface examination of low carbon steel by applying the extract of Musa acuminata. Surfaces and Interfaces 2020, 18, https://doi.org/10.1016/j.surfin.2020.100436.

2. Mofidabadi, A.H.J.; Bahlakeh, G.; Ramezanzadeh, B. Explorations of the adhesion and anti-corrosion properties of the epoxy coating on the carbon steel surface modified by Eu2O3 nanostructured film. J. Mol. Liq.2020, 314, https://doi.org/10.1016/j.molliq.2020.113658.

3. El Faydy, M.; Benhiba, F.; About, H.; Kerroum, Y.; Guenbour, A.; Lakhrissi, B.; Warad, I.; Verma, C.; Sherif, E.S.M.; Ebenso, E.E.; Zarrouk, A. Experimental and computational investigations on the anticorrosive and adsorption behavior of 7-N,N'-dialkyaminomethyl-8-Hydroxyquinolines on C40E steel surface in acidic medium. J. Colloid Interface Sci.2020, 576, 330-344, https://doi.org/10.1016/j.jcis.2020.05.010.

4. Majd, M.T.; Shahrabi, T.; Ramezanzadeh, B. Production of an eco-friendly anti-corrosion ceramic base nanostructured hybrid-film based on Nd (III)-C7H6N2 on the mild steel surface; Electrochemical and surface studies. Constr. Build. Mater.2019, 221, 456-468, https://doi.org/10.1016/j.conbuildmat.2019.06.122.

5. Rouifi, Z.; Benhiba, F.; Faydy, M. El; Laabaissi, T.; About, H.; Oudda, H.; Warad, I.; Guenbour, A.; Lakhrissi, B.; Zarrouk, A. Performance and computational studies of new soluble triazole as corrosion inhibitor for carbon steel in HCl. Chem. Data Collect.2019, 22, https://doi.org/10.1016/j.cdc.2019.100242.

6. El aoufir, Y.; Zehra, S.; Lgaz, H.; Chaouiki, A.; Serrar, H.; Kaya, S.; Salghi, R.; AbdelRaheem, S.K.; Boukhris, S.; Guenbour, A.; Chung, I.M. Evaluation of inhibitive and adsorption behavior of thiazole-4carboxylates on mild steel corrosion in HCl. Colloids Surfaces A Physicochem. Eng. Asp.2020, 606, https://doi.org/10.1016/j.colsurfa.2020.125351.

7. Bourazmi, H.; Tabyaoui, M.; El Hattabi, L.; Aoufir, Y.E.; Taleb, M. Methanolic Extract of Salvia Officinalis plant as a green inhibitor for the corrosion of carbon steel in $1 \mathrm{M} \mathrm{HCl}$. J. Mater. Environ. Sci2018, 9, 928938.

8. $\quad$ Laourayed, M.; El Moudane, M.; Khachani, M.; Boudalia, M.; Guenbour, A.; Bellaouchou, A.; Zarrouk, A. Thermal, structural and corrosion inhibition performances of a new phosphate glasses on mild steel in $\mathrm{HCl}$ medium. Chem. Data Collect.2019, 24, https://doi.org/10.1016/j.cdc.2019.100305. 
9. Loto, R.T.; Olukeye, T.; Okorie, E. Synergistic combination effect of clove essential oil extract with basil and atlas cedar oil on the corrosion inhibition of low carbon steel. South African J. Chem. Eng.2019, 30, 2841, https://doi.org/10.1016/j.sajce.2019.08.001.

10. Elaissi, A.; Salah, K.H.; Mabrouk, S.; Larbi, K.M.; Chemli, R.; Harzallah-Skhiri, F. Antibacterial activity and chemical composition of 20 Eucalyptus species' essential oils. Food Chem.2011, 129, 1427-1434, https://doi.org/10.1016/j.foodchem.2011.05.100.

11. Tabatabaei majd, M.; Bahlakeh, G.; Dehghani, A.; Ramezanzadeh, B.; Ramezanzadeh, M. Combined molecular simulation, DFT computation and electrochemical studies of the mild steel corrosion protection against $\mathrm{NaCl}$ solution using aqueous Eucalyptus leaves extract molecules linked with zinc ions. J. Mol. Liq.2019, 294, https://doi.org/10.1016/j.molliq.2019.111550.

12. Dehghani, A.; Bahlakeh, G.; Ramezanzadeh, B. Green Eucalyptus leaf extract: A potent source of bio-active corrosion inhibitors for mild steel. Bioelectrochemistry2019, 130, https://doi.org/10.1016/j.bioelechem.2019.107339.

13. Clevenger, J.F. American pharmaceutical association 345 apparatus for t h e determination of volatile oil.J. Pharm. Sci.1928, 17, 345-349.

14. Mishrif, M.R.; Noor El-Din, M.R.; Khamis, E.A. Utilization of ethoxylated pentamine oleamide as new Gemini surfactants for corrosion inhibition effectiveness in $1 \mathrm{M} \mathrm{HCl} \mathrm{solution.} \mathrm{Egypt.} \mathrm{J.} \mathrm{Pet.2018,} \mathrm{27,} \mathrm{1357-}$ 1370, https://doi.org/10.1016/j.ejpe.2018.09.004.

15. Olawale, O.; Bello, J.O.; Ogunsemi, B.T.; Uchella, U.C.; Oluyori, A.P.; Oladejo, N.K. Optimization of chicken nail extracts as corrosion inhibitor on mild steel in 2M H2SO4. Heliyon 2019, 5, https://doi.org/10.1016/j.heliyon.2019.e02821.

16. Cuevas-Arteaga, C.; Uruchurtu-Chavarín, J.; Porcayo-Calderon, J.; Izquierdo-Montalvo, G.; Gonzalez, J. Study of molten salt corrosion of HK-40m alloy applying linear polarization resistance. And conventional weight loss techniques. Corros. Sci.2004, 46, 2663-2679, https://doi.org/10.1016/j.corsci.2004.03.002.

17. Al-Baghdadi, S.B.; Hashim, F.G.; Salam, A.Q.; Abed, T.K.; Gaaz, T.S.; Al-Amiery, A.A.; Kadhum, A.A.H.; Reda, K.S.; Ahmed, W.K. Synthesis and corrosion inhibition application of NATN on mild steel surface in acidic media complemented with DFT studies. Results Phys.2018, 8, 1178-1184, https://doi.org/10.1016/j.rinp.2018.02.007.

18. Li, X.; Mu, G. Tween-40 as corrosion inhibitor for cold rolled steel in sulphuric acid: Weight loss study, electrochemical characterization, and AFM. Appl. Surf. Sci.2005, 252, 1254-1265, https://doi.org/10.1016/j.apsusc.2005.02.118.

19. Dutta, A.; Saha, S.K.; Banerjee, P.; Patra, A.K.; Sukul, D. Evaluating corrosion inhibition property of some Schiff bases for mild steel in $1 \mathrm{M} \mathrm{HCl}$ : Competitive effect of the heteroatom and stereochemical conformation of the molecule. RSC Adv.2016, 6, 74833-74844, https://doi.org/10.1039/c6ra03521c.

20. Zhang, J.; Gong, X.L.; Yu, H.H.; Du, M. The inhibition mechanism of imidazoline phosphate inhibitor for Q235 steel in hydrochloric acid medium. Corros. Sci.2011, 53, 3324-3330, https://doi.org/10.1016/j.corsci.2011.06.008.

21. Athar, M.; Ali, H.; Quraishi, M.A. Corrosion inhibition of carbon steel in hydrochloric acid by organic compounds containing heteroatoms. Br. Corros. J.2002, 37, 155-158, https://doi.org/10.1179/000705902225002376.

22. Hafez, B.; Mokhtari, M.; Elmsellem, H.; Steli, H. Environmentally friendly inhibitor of the corrosion of mild steel: Commercial oil of Eucalyptus. Int. J. Corros. Scale Inhib.2019, 8, 573-585, https://doi.org/10.17675/2305-6894-2019-8-3-8.

23. Ouakki, M.; Galai, M.; Rbaa, M.; Abousalem, A.S.; Lakhrissi, B.; Rifi, E.H.; Cherkaoui, M. Quantum chemical and experimental evaluation of the inhibitory action of two imidazole derivatives on mild steel corrosion in sulphuric acid medium. Heliyon 2019, 5, https://doi.org/10.1016/j.heliyon.2019.e02759.

24. Hsissou, R.; Abbout, S.; Seghiri, R.; Rehioui, M.; Berisha, A.; Erramli, H.; Assouag, M.; Elharfi, A. Evaluation of corrosion inhibition performance of phosphorus polymer for carbon steel in [1 M] $\mathrm{HCl}$ : Computational studies (DFT, MC and MD simulations). J. Mater. Res. Technol.2020, 9, 2691-2703, https://doi.org/10.1016/j.jmrt.2020.01.002.

25. Zhao, A.; Sun, H.; Chen, L.; Huang, Y.; Lu, X.; Mu, B.; Gao, H.; Wang, S.; Singh, A. Electrochemical studies of bitter gourd (Momordica charantia) fruits as ecofriendly corrosion inhibitor for mild steel in $1 \mathrm{M}$ HCl solution. Int. J. Electrochem. Sci.2019, 14, 6814-6825, https://doi.org/10.20964/2019.07.75.

26. Akinbulumo, O.A.; Odejobi, O.J.; Odekanle, E.L. Thermodynamics and adsorption study of the corrosion inhibition of mild steel by Euphorbia heterophylla L. extract in $1.5 \mathrm{M} \mathrm{HCl}$. Results Mater.2020, 5, https://doi.org/10.1016/j.rinma.2020.100074.

27. El Faydy, M.; Touir, R.; Ebn Touhami, M.; Zarrouk, A.; Jama, C.; Lakhrissi, B.; Olasunkanmi, L.O.; Ebenso, E.E.; Bentiss, F. Corrosion inhibition performance of newly synthesized 5-alkoxymethyl-8hydroxyquinoline derivatives for carbon steel in $1 \mathrm{M} \mathrm{HCl}$ solution: Experimental, DFT and Monte Carlo simulation studies. Phys. Chem. Chem. Phys.2018, 20, 20167-20187, https://doi.org/10.1039/c8cp03226b.

28. Adesusi, O.M.; Adetunji, O.R.; Ismaila, S.O.; Dare, E.O.; Erinle, T.J.; Akinpelu, O.O. Electrochemical Inhibitory Effects of Non-edible Vegetable Oils on Low-Alloyed Low Carbon Steel in H2SO4. J. Fail. Anal. Prev.2020, 20, 159-172, https://doi.org/10.1007/s11668-020-00808-X. 
29. Kamali Ardakani, E.; Kowsari, E.; Ehsani, A. Imidazolium-derived polymeric ionic liquid as a green inhibitor for corrosion inhibition of mild steel in $1.0 \mathrm{M} \mathrm{HCl}$ : Experimental and computational study. Colloids Surfaces A Physicochem. Eng. Asp.2020, 586, https://doi.org/10.1016/j.colsurfa.2019.124195.

30. Deyab, M.A.; Zaky, M.T.; Nessim, M.I. Inhibition of acid corrosion of carbon steel using four imidazolium tetrafluoroborates ionic liquids. J. Mol. Liq.2017, 229, 396-404, https://doi.org/10.1016/j.molliq.2016.12.092.

31. Rajendraprasad, S.; Ali, S.; Prasanna, B.M. Electrochemical Behavior of N 1-(3-Methylphenyl)Piperidine1,4-Dicarboxamide as a Corrosion Inhibitor for Soft-Cast Steel Carbon Steel in $1 \mathrm{M} \mathrm{HCl}$. J. Fail. Anal. Prev.2020, 20, 235-241, https://doi.org/10.1007/s11668-020-00824-X.

32. Yan, T.; Zhang, S.; Feng, L.; Qiang, Y.; Lu, L.; Fu, D.; Wen, Y.; Chen, J.; Li, W.; Tan, B. Investigation of imidazole derivatives as corrosion inhibitors of copper in sulfuric acid: Combination of experimental and theoretical researches. J. Taiwan Inst. Chem. Eng.2020, 106, 118-129, https://doi.org/10.1016/j.jtice.2019.10.014.

33. Batah, A.; Anejjar, A.; Bammou, L.; Belkhaouda, M.; Salghi, R. Effect of apricot almond oil as green inhibitor for steel corrosion in hydrochloric media. Port. Electrochim. Acta2020, 38, 201-214, https://doi.org/10.4152/pea.202004201.

34. El Faydy, M.; Lakhrissi, B.; Jama, C.; Zarrouk, A.; Olasunkanmi, L.O.; Ebenso, E.E.; Bentiss, F. Electrochemical, surface and computational studies on the inhibition performance of some newly synthesized 8-hydroxyquinoline derivatives containing benzimidazole moiety against the corrosion of carbon steel in phosphoric acid environment. J. Mater. Res. Technol.2020, 9, 727-748, https://doi.org/10.1016/j.jmrt.2019.11.014.

35. Singh, A.; Ansari, K.R.; Chauhan, D.S.; Quraishi, M.A.; Lgaz, H.; Chung, I.M. Comprehensive investigation of steel corrosion inhibition at macro/micro level by ecofriendly green corrosion inhibitor in $15 \% \mathrm{HCl}$ medium. J. Colloid Interface Sci.2020, 560, 225-236, https://doi.org/10.1016/j.jcis.2019.10.040.

36. Salarvand, Z.; Amirnasr, M.; Talebian, M.; Raeissi, K.; Meghdadi, S. Enhanced corrosion resistance of mild steel in $1 \mathrm{M} \mathrm{HCl}$ solution by trace amount of 2-phenyl-benzothiazole derivatives: Experimental, quantum chemical calculations and molecular dynamics (MD) simulation studies. Corros. Sci.2017, 114, 133-145, https://doi.org/10.1016/j.corsci.2016.11.002.

37. Boudalia, M.; Guenbour, A.; Bellaouchou, A.; Fernandez-Domene, R.M.; Garcia-Anton, J. Corrosion behaviour of a highly alloyed austenitic alloy UB6 in contaminated phosphoric acid. Int. J. Corros.2013, 2013, 1-9, https://doi.org/10.1155/2013/363826.

38. Gao, H.; Li, Q.; Dai, Y.; Luo, F.; Zhang, H.X. High efficiency corrosion inhibitor 8-hydroxyquinoline and its synergistic effect with sodium dodecylbenzenesulphonate on AZ91D magnesium alloy. Corros. Sci.2010, 52, 1603-1609, https://doi.org/10.1016/j.corsci.2010.01.033.

39. Rbaa, M.; Benhiba, F.; Obot, I.B.; Oudda, H.; Warad, I.; Lakhrissi, B.; Zarrouk, A. Two new 8hydroxyquinoline derivatives as an efficient corrosion inhibitors for mild steel in hydrochloric acid: Synthesis, electrochemical, surface morphological, UV-visible and theoretical studies. J. Mol. Liq.2019, 276, 120-133, https://doi.org/10.1016/j.molliq.2018.11.104.

40. He, T.; Emori, W.; Zhang, R.H.; Okafor, P.C.; Yang, M.; Cheng, C.R. Detailed characterization of Phellodendron chinense Schneid and its application in the corrosion inhibition of carbon steel in acidic media. Bioelectrochemistry2019, 130, https://doi.org/10.1016/j.bioelechem.2019.107332.

41. Singh, P.; Chauhan, D.S.; Chauhan, S.S.; Singh, G.; Quraishi, M.A. Chemically modified expired Dapsone drug as environmentally benign corrosion inhibitor for mild steel in sulphuric acid useful for industrial pickling process. J. Mol. Liq.2019, 286, https://doi.org/10.1016/j.molliq.2019.110903.

42. Thirumangalam Karunanithi, B.; Chellappa, J. Adsorption and inhibition properties of Tephrosia Purpurea as corrosion inhibitor for mild steel in sulphuric acid solution. J. Dispers. Sci. Technol.2019, 40, 1441-1450, https://doi.org/10.1080/01932691.2018.1516150. 